\title{
Geochemical mapping applications to forensics and intelligence
}

\author{
PATRICE DE CARITAT ${ }^{1}$, BRENDA WOODS ${ }^{2}$, PAUL \\ ROFFEY $^{2}$, JURIAN HOOGEWERFF ${ }^{3}$ AND JENNIFER \\ YOUNG $^{4}$
}

${ }^{1}$ Geoscience Australia

${ }^{2}$ Australian Federal Police

${ }^{3}$ University of Canberra

${ }^{4}$ Flinders University

Presenting Author: patrice.decaritat@ga.gov.au

Geochemical surveys deliver fundamental data, information and knowledge about the concentration and spatial distribution of chemical elements, isotopes and compounds in the natural environment. Typically near-surface sampling media, such as soil, sediment, outcropping rocks and stream or groundwater, are used. The application of such datasets to mineral exploration, environmental management, and geomedicine has been widely documented. In this presentation I reflect on a sabbatical experience with the Australian Federal Police (AFP) in 20172018 that allowed me to extend the interpretation of geochemical survey data beyond these established applications. In particular, with my collaborators we explore ways in which geochemical survey data and maps can be used to indicate the provenance of an evidentiary sample collected at a crime scene or obtained for instance from items belonging to a suspect intercepted at border entry. Because soils are extremely diverse mineralogically, geochemically and biologically, it should theoretically be possible to exclude very large swathes of territory (>90\%) from further provenancing investigation using soil data. In a collaboration between Geoscience Australia (GA), the AFP and the University of Canberra (UC), a recent geochemical survey of the urban/suburban Canberra region in southeastern Australia is being used as a testbed for developing different approaches to forensic applications of geochemical surveys. A predictive soil provenancing method at the national scale was also developed and tested for application where no actual detailed, fit-forpurpose geochemical survey data exist. Over the next few years, GA, AFP and UC are collaborating with Flinders University to add biome data from soil and soil-derived dust to further improve the provenancing technique. 